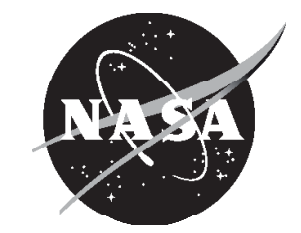

Assessment of Microphysical Models in the National Combustion Code (NCC) for Aircraft Particulate Emissions: Particle Loss in Sampling Lines

Thomas Wey and Nan-Suey Liu

Glenn Research Center, Cleveland, Ohio 


\section{NASA STI Program . . . in Profile}

Since its founding, NASA has been dedicated to the advancement of aeronautics and space science. The NASA Scientific and Technical Information (STI) program plays a key part in helping NASA maintain this important role.

The NASA STI Program operates under the auspices of the Agency Chief Information Officer. It collects, organizes, provides for archiving, and disseminates NASA's STI. The NASA STI program provides access to the NASA Aeronautics and Space Database and its public interface, the NASA Technical Reports Server, thus providing one of the largest collections of aeronautical and space science STI in the world. Results are published in both non-NASA channels and by NASA in the NASA STI Report Series, which includes the following report types:

- TECHNICAL PUBLICATION. Reports of completed research or a major significant phase of research that present the results of NASA programs and include extensive data or theoretical analysis. Includes compilations of significant scientific and technical data and information deemed to be of continuing reference value. NASA counterpart of peer-reviewed formal professional papers but has less stringent limitations on manuscript length and extent of graphic presentations.

- TECHNICAL MEMORANDUM. Scientific and technical findings that are preliminary or of specialized interest, e.g., quick release reports, working papers, and bibliographies that contain minimal annotation. Does not contain extensive analysis.

- CONTRACTOR REPORT. Scientific and technical findings by NASA-sponsored contractors and grantees.

- CONFERENCE PUBLICATION. Collected papers from scientific and technical conferences, symposia, seminars, or other meetings sponsored or cosponsored by NASA.

- SPECIAL PUBLICATION. Scientific, technical, or historical information from NASA programs, projects, and missions, often concerned with subjects having substantial public interest.

- TECHNICAL TRANSLATION. Englishlanguage translations of foreign scientific and technical material pertinent to NASA's mission.

Specialized services also include creating custom thesauri, building customized databases, organizing and publishing research results.

For more information about the NASA STI program, see the following:

- Access the NASA STI program home page at http://www.sti.nasa.gov

- E-mail your question via the Internet to help@ sti.nasa.gov

- Fax your question to the NASA STI Help Desk at 301-621-0134

- Telephone the NASA STI Help Desk at 301-621-0390

- Write to: NASA Center for AeroSpace Information (CASI) 7115 Standard Drive Hanover, MD 21076-1320 


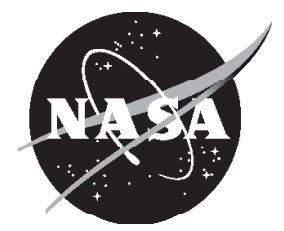

\section{Assessment of Microphysical Models in the National Combustion Code (NCC) for Aircraft Particulate Emissions: Particle Loss in Sampling Lines}

Thomas Wey and Nan-Suey Liu

Glenn Research Center, Cleveland, Ohio

Prepared for the

47th Aerospace Sciences Meeting

sponsored by the American Institute of Aeronautics and Astronautics

Orlando, Florida, January 5-8, 2009

National Aeronautics and

Space Administration

Glenn Research Center

Cleveland, Ohio 44135 


\section{Acknowledgments}

This work is supported by the NASA Fundamental Aeronautics Program. We would like to thank Drs. Chowen Wey and

Dan Bulzan for useful discussions on the selection of the validation data. The data of the APEX3 sampling lines are provided by Dr. Bruce Anderson, and the data of UTRC sampling lines are provided by Dr. David Liscinsky.

This report is a formal draft or working paper, intended to solicit comments and ideas from a technical peer group.

This report is a preprint of a paper intended for presentation at a conference.

Because changes may be made before formal publication, this preprint is made available with the understanding that it will not be cited or reproduced without the permission of the author.

This work was sponsored by the Fundamental Aeronautics Program at the NASA Glenn Research Center.

Level of Review: This material has been technically reviewed by technical management.

Available from

NASA Center for Aerospace Information 7115 Standard Drive

Hanover, MD 21076-1320
National Technical Information Service 5285 Port Royal Road Springfield, VA 22161 


\title{
Assessment of Microphysical Models in the National Combustion Code (NCC) for Aircraft Particulate Emissions: Particle Loss in Sampling Lines
}

\author{
Thomas Wey and Nan-Suey Liu \\ National Aeronautics and Space Administration \\ Glenn Research Center \\ Cleveland, Ohio 44135
}

\begin{abstract}
Summary
This paper at first describes the fluid network approach recently implemented into the National Combustion Code (NCC) for the simulation of transport of aerosols (volatile particles and soot) in the particulate sampling systems. This network-based approach complements the other two approaches already in the NCC, namely, the lower-order temporal approach and the CFD-based approach. The accuracy and the computational costs of these three approaches are then investigated in terms of their application to the prediction of particle losses through sample transmission and distribution lines. Their predictive capabilities are assessed by comparing the computed results with the experimental data. The present work will help establish standard methodologies for measuring the size and concentration of particles in high-temperature, high-velocity jet engine exhaust. Furthermore, the present work also represents the first step of a long term effort of validating physics-based tools for the prediction of aircraft particulate emissions.
\end{abstract}

\section{Introduction}

Aircraft emissions contribute to climate change in the atmosphere and air pollution in the neighborhood of airports. Assessment of the magnitude of their environmental impacts calls for a better understanding of the formation and the subsequent development of gaseous pollutants, aerosols (volatile particles and soot), and their precursors in the internal and in the plume of the jet engines operating over the full range from ground to flight altitude. The volatile nature of aerosols introduces difficulties in their repeatable and accurate measurement because their concentration and size can be quite sensitive to the sampling conditions and procedures. These difficulties are sometimes further compounded by the necessity of in-situ measurements, i.e., sampling from aircraft in flight. Clearly, the ability to predict the effects of sampling conditions and procedures on the aerosol behavior will greatly assist the development of sampling techniques and the optimization of sampling procedures for making quantitatively accurate measurements of particulate emissions.

A multi-dimensional CFD-based capability for modeling and simulation of the aviation-sourced particle evolution in flow paths is now available in the National Combustion Code (NCC). A detailed description of this multi-dimensional approach can be found in references 1 and 2. The CFD-based simulation is very computing intensive, and, quite often, a lower-order temporal approach is used to capture the overall evolution, a detailed description of this approach is given in reference 3 . This lowerorder temporal approach greatly alleviates the computing resource requirement, but it may not be appropriate for certain flow configurations and conditions. To bridge the gap between the CFD-based approach and the lower-order temporal approach, we have implemented the fluid network approach into the NCC, the details of the adopted fluid network approach will be presented in the next section.

The NASA-sponsored Aircraft Particle Emission Experiment (APEX) field test series to measure the size and concentration of particles in the jet engine exhausts have produced highly variable results (ref. 4). To better understand the sources of this variation, NASA recently sponsored additional field experiments and laboratory experiments to evaluate jet engine exhaust sampling and measurement systems. One of the 
focused area is the assessment of size and mass-dependent particle loss through the sampling lines. These tests produced several sets of particle line loss data, which are used in the present effort to validate the predicted results obtained from the three different modeling and simulation approaches mentioned above. Comparison between the measured data and computed results are discussed in a later section.

\section{Modeling and Simulation}

Same Chemical and microphysical models for aircraft particulates are used in the three different levels of approach. The finite rate kinetics models used are those for conditions intermediate between combustion and atmospheric chemistry. The particle transport equations are based on the multi-bin Eulerian framework. The microphysical models include sulfate and nitrate aerosol precursors, thermophoresis, coagulation, nucleation, soot activation, condensation/evaporation, and interaction between the gaseous species and the particles. Generally speaking, the CFD-based simulation tightly integrates fluid dynamics, chemistry, and particle microphysics. The lower-order temporal simulation is one in which chemistry and particle microphysics are driven by averaged flow parameters specified as a function of time. Details of these two approaches have been reported in references 1, 2, and 3 .

Motivated by the practical need to simulate the often complicated sampling line system in an efficient and timely manner, we added an additional option based on the fluid network approach, which takes into account the complex internal flow and thermal effects within the fluid systems. Although here the intended application is for the particle sampling line system, the fluid network approach is, in general, a system level method and is not restricted to any specific geometries or configurations. SINDA/FLUINT (ref. 5) and GFSSP (ref. 6) are two of many system simulation programs widely used by NASA for internal flows. This work adopts similar formulation of the momentum equation as that in GFSSP. A relatively detailed description of the fluid network approach used in this work follows.

The conservation equations for the gaseous flow and the transport equations for the aerosols are

Continuity equation

$$
\frac{d}{d t} \iiint_{V} \rho d V+\iint_{A} \rho \vec{u} \cdot d \vec{A}=0
$$

Species transport equation

$$
\frac{d}{d t} \iiint_{V} \rho_{m} d V+\iint_{A} \rho_{m} \vec{u} \cdot d \vec{A}=\iint_{A} \rho D_{e f f} \nabla\left(\frac{\rho_{m}}{\rho}\right) \cdot d \vec{A}+\iiint_{V} \dot{w}^{\prime \prime \prime}{ }_{m} d V
$$

Momentum equation

$$
\frac{d}{d t} \iiint_{V} \rho \vec{u} d V+\iint_{A} \rho \vec{u} \vec{u} \cdot d \vec{A}=-\iint_{A} p d \vec{A}+\iint_{A} \tau \cdot d \vec{A}
$$

Energy equation

$$
\frac{d}{d t} \iiint_{V} \rho E d V+\iint_{A} \rho E \vec{u} \cdot d \vec{A}=-\iint_{A} p \vec{u} \cdot d \vec{A}-\iint_{A} \vec{q} \cdot d \vec{A}+\iint_{A} \vec{u} \cdot \tau \cdot d \vec{A}
$$

Aerosol general dynamic equation

$$
\frac{d}{d t} \iiint_{V} N_{k} d V+\iint_{A} N_{k} \vec{u} \cdot d \vec{A}=\iint_{A}\left(D_{M}+\frac{2 v_{t}}{3 \sqrt{C_{u} f_{u}}}\right) \nabla N_{k} \cdot d \vec{A}
$$




$$
\begin{gathered}
+\left.\iiint_{V} \frac{d N_{k}}{d t}\right|_{\text {micro }} d V, \\
k=1, \cdots, M_{B}
\end{gathered}
$$

where

$$
\begin{gathered}
\vec{q}=-\kappa \nabla T \\
\tau=-\frac{2}{3} \mu(\nabla \cdot \vec{u}) \mathbf{I}+\frac{1}{2} \mu\left(\nabla \overrightarrow{\mathbf{u}}+(\nabla \overrightarrow{\mathbf{u}})^{\mathbf{T}}\right),
\end{gathered}
$$

$V$ is an arbitrary control volume with control surface $A, \rho$ is the fluid density, $\rho_{m}$ is the partial density of species $m, \dot{w}_{m}^{\prime \prime \prime}$ is the production rate of species $m$ per unit volume, $\vec{u}$ is the flow velocity in a stationary Cartesian coordinate system, $E$ is the total energy density, $p$ is the static pressure, $\tau$ is the viscous stress tensor, $\vec{q}$ is the heat flux vector, $D_{\text {eff }}$ is the effective mass diffusivity coefficient which is equal to $\frac{\mu_{t}+\mu}{\rho S c}$, $\kappa, \mu$, and $\mu_{t}$ are the thermal conductivity, laminar viscosity and turbulent viscosity, respectively. For gas, the Schmidt number $(S c)$ is about $1 . N_{k}$ is the number density of particles in size bin $k, M_{B}$ is the total number of the size bins, $v_{t}$ is turbulent kinematic viscosity, $C_{u}$ is $0.09, f_{u}$ is the damping function of the turbulence model. Detailed definitions of variables can be found in reference 1.

In the framework of the fluid network approach, the entire fluid system is considered as consisting of a number of lumps connected by paths. Each lump has its own finite volume and is joined by path(s) to other lump(s), thus a network is formed. The fluid properties, such as density, temperature, pressure, viscosity, and mass fractions are computed and stored at the centers of lumps, while a unidirectional velocity is computed and stored in each path; its value can be less than zero, equal to zero or larger than zero. In general, the number of paths connecting to a lump can vary from lump to lump. In this work, the paths enter a lump are called inward paths, while the paths leave a lump are called outward paths. This definition facilitates the implementation of upwind differencing scheme and implicit time integration.

In the following, the subscript for a path variable will be either $j$ or $\ell$, and the subscript for a lump property will be $i$. This is the staggered-grid arrangement commonly used in many CFD schemes. In addition, a predictor-corrector algorithm is adopted to advance the temporal evolution of the variables.

In the predictor step, a previously computed pressure is employed to solve the momentum equation for the path velocity,

$$
\begin{aligned}
& \frac{m_{j} u_{j}^{*}-m_{j} u_{j}^{n}}{\Delta t}+\max \left(\dot{m}_{j}, 0\right)\left(u_{j}^{*}-u_{j u w}^{*}\right)+ \\
& \max \left(-\dot{m}_{j}, 0\right)\left(u_{j}^{*}-u_{j d w}^{*}\right)=\left(p_{u w j}-p_{d w j}\right) A_{j}-K_{f j} \dot{m}_{j}\left|\dot{m}_{j}\right| A_{j}+S_{u j}
\end{aligned}
$$

where the subscript juw points to the upwind path of path $j$, while the subscript $j d w$ points to the downwind path of path $j$. Conversely the subscript $u w j$ points to the upwind lump of path $j$, while the subscript $d w j$ points to the downwind lump of path $j$. Here, $u_{j}$ is the velocity of path $j, \dot{m}_{j}$ is the mass flow rate of path $j, K_{f j}$ accounts for the laminar and turbulent viscous effects associated with the path $j$, it is a function of the geometry entities and the characteristics of the paths. For typical pipes, it is usually a function of Darcy friction factor. A comprehensive definition of $K_{f j}$ is given in reference $6 . A_{j}$ is the cross sectional area of path $j . S_{u j}$ represents a generic source term such as a pump or additional forces exerting on a path. 
Equation (6) can be recast into

$$
\begin{gathered}
{\left[\frac{m_{j}}{\Delta t}+K_{f j} \rho_{j}\left|\dot{m}_{j}\right| A_{j}^{2}+\max \left(\dot{m}_{j}, 0\right)+\max \left(-\dot{m}_{j}, 0\right)\right] u_{j}^{*}} \\
=\max \left(\dot{m}_{j}, 0\right) u_{j u w}^{*}+\max \left(-\dot{m}_{j}, 0\right) u_{j d w}^{*}+\left(p_{u w j}-p_{d w j}\right) A_{j}+\frac{m_{j} u_{j}^{n}}{\Delta t}+S_{u j}
\end{gathered}
$$

In the subsequent discussion, we will use the variable $\dot{M}_{t j}$ which is defined as

$$
\dot{M}_{t j}=\frac{\dot{m}_{j}}{\Delta t}+K_{f j} \rho_{j}\left|\dot{m}_{j}\right| A_{j}^{2}+\max \left(\dot{m}_{j}, 0\right)+\max \left(-\dot{m}_{j}, 0\right)
$$

The energy equation is formulated in terms of the conservation of the enthalpy.

$$
\begin{gathered}
\frac{m_{i} h_{i}^{*}-m_{i} h_{i}^{n}}{\Delta t}+\sum_{\ell=1}^{\text {outward }} \max \left(-\dot{m}_{\ell}, 0\right)\left(h_{i}^{*}-h_{d w \ell}^{*}\right)-\sum_{j=1}^{\text {inward }} \max \left(\dot{m}_{j}, 0\right)\left(h_{i}^{*}-h_{u w j}^{*}\right) \\
=\sum_{\ell=1}^{\text {outward }}\left[\left(\frac{\max \left(-\dot{m}_{\ell}, 0\right)}{\dot{m}_{\ell}} u_{\ell} A_{\ell}\right)\left[\left(p_{u w \ell}-p_{d w \ell}\right)+K_{f \ell} \dot{m} \ell \ell_{\ell}^{2}\right)+\kappa_{\ell} \frac{A_{\ell}}{L_{\ell}}\left(T_{d w \ell}-T_{i}\right)+H_{\ell} A_{w \ell}\left(T_{w a l l}-T_{a w}\right)_{\ell}\right] \\
\left.+\sum_{j=1}^{\text {inward }}\left[\left(\frac{\max \left(\dot{m}_{j}, 0\right)}{\dot{m}_{j}} u_{j} A_{j}\right)\left[\left(p_{d w j}-p_{u w j}\right)+K_{f j} \dot{m}_{j}^{2}\right)\right]+\kappa_{j} \frac{A_{j}}{L_{j}}\left(T_{u w j}-T_{i}\right)+H_{j} A_{w j}\left(T_{w a l l}-T_{a w}\right)_{j}\right] \\
+S_{h i}
\end{gathered}
$$

where the convective heat transfer coefficient is $H=\rho C p|u| S t$, and $S t=\frac{f}{2} \operatorname{Pr}^{-2 / 3}$ is the Stanton number given by modified Reynolds analogy for turbulent flow in pipes, where $f$ is the Fanning friction factor of the path, and $\operatorname{Pr}$ is the Prandtl number. $T_{\text {wall }}$ is the specified wall temperature and $T_{a w}$ is the adiabatic wall temperature. $L$ is the normal distance of a path. $A_{w j}$ is the wetted surface area of path $j . S_{h j}$ represents a generic source term for the energy equation such as the heat transfer from the surrounding solid.

In the second, i.e., the corrector step, the continuity equation is formulated in terms of a pressure correction. It is assumed that the velocity is a function of the pressure gradient which, in turn, is a function of the two pressures on each side of a velocity path. Now consider a path $j$, which is connected to a upwind lump denoted by upj and a downwind lump denoted by $d w j$, applying a Taylor series expansion along the pressure coordinates, one has

$$
u_{j}=u_{j}^{*}+\frac{\partial u_{j}}{\partial p_{u w j}}\left(p_{u w j}-p_{u w j}^{*}\right)+\frac{\partial u_{j}}{\partial p_{d w j}}\left(p_{d w j}-p_{d w j}^{*}\right)
$$

Using the definition of $\dot{M}_{t j}$ and equation (7), one finds 


$$
\frac{\partial u_{j}}{\partial p_{u w j}}=\frac{A_{j}}{\dot{M}_{t j}}, \frac{\partial u_{j}}{\partial p_{d w j}}=-\frac{A_{j}}{\dot{M}_{t j}}
$$

thus, the new velocity can be expressed as a function of the previously predicted velocity and the pressure change via

$$
u_{j}=u_{j}^{*}+\frac{A_{j}}{\dot{M}_{t j}}\left(\Delta p_{u w j}-\Delta p_{d w j}\right)
$$

Now applying the continuity equation to a lump yields

$$
\frac{m_{i}-m_{i}^{n}}{\Delta t}+\sum_{\ell=1}^{\text {outward }} \rho_{\ell} u_{\ell} A_{\ell}-\sum_{j=1}^{\text {inward }} \rho_{j} u_{j} A_{j}=0
$$

Like other pressure-based methodology, the pressure change and the density change are related through a derivative evaluated at the condition of constant temperature:

$$
\rho=\rho^{*}+\Delta \rho=\rho^{*}+\Delta p\left[\frac{d \rho}{d p}\right]_{T}
$$

where, for the perfect gas, $\left[\frac{d \rho}{d p}\right]_{T}=\frac{1}{R T}$, and, for the high pressure fluid model, $\left[\frac{d \rho}{d p}\right]_{T}=\frac{\gamma}{a^{2}}$.

Substituting equations (9) and (11) into equation (10), and then neglecting the second order changes while applying the first-order-upwind differencing to the mass flux in the paths, one obtains the final form of the pressure correction equation

$$
\begin{gathered}
\frac{V_{i} \Delta p_{i}}{R_{i} T_{i} \Delta t}+\sum_{\ell=1}^{\text {outward }}\left[\max \left(-\frac{A_{\ell} u_{\ell}^{*}}{R_{\ell} T_{\ell}}, 0\right)+\frac{\rho_{\ell}^{*} A_{\ell}^{2}}{\dot{M}_{t \ell}}\right]\left(\Delta p_{i}-\Delta p_{d w \ell}\right) \\
+\sum_{j=1}^{\text {inward }}\left[\max \left(\frac{A_{j} u_{j}^{*}}{R_{j} T_{j}}, 0\right)+\frac{\rho_{j}^{*} A_{j}^{2}}{\dot{M}_{t j}}\right]\left(\Delta p_{i}-\Delta p_{u w j}\right) \\
=\sum_{\ell=1}^{\text {outward }}\left[\max \left(-A_{\ell} u_{\ell}^{*}, 0\right) \rho_{d w \ell}^{*}-\max \left(A_{\ell} u_{\ell}^{*}, 0\right) \rho_{i}^{*}\right] \\
+\sum_{j=1}^{\text {inward }}\left[\max \left(A_{j} u_{j}^{*}, 0\right) \rho_{u w j}^{*}-\max \left(-A_{j} u_{j}^{*}, 0\right) \rho_{i}^{*}\right] \\
-\frac{m_{i}^{*}-m_{i}^{n}}{\Delta t}
\end{gathered}
$$

where $V_{i}$ is the volume of lump $i$. Once the pressure is obtained, the field values of the path velocity are corrected according to 


$$
u_{j}^{n+1}=u_{j}^{*}+A_{j} \frac{\left(\Delta p_{u w j}-\Delta p_{d w j}\right)}{\dot{M}_{t j}}
$$

and the enthalpy values are corrected according to

$$
\begin{gathered}
h_{i}^{n+1}=h_{i}^{*}+\frac{1}{\dot{M}_{t i}}\left(\frac{\Delta p_{i} V_{i}}{\Delta t}\right. \\
+\sum_{\ell=1}^{\text {outward }}\left[0.5\left(\Delta p_{i}+\Delta p_{d w \ell}\right) A_{\ell} u_{\ell}^{n+1}\right] \\
\left.-\sum_{j=1}^{\text {inward }}\left[0.5\left(\Delta p_{i}+\Delta p_{u w j}\right) A_{j} u_{j}^{n+1}\right]\right)
\end{gathered}
$$

where $\dot{M}_{t i}$ is the average of surrounding $\dot{M}_{t}$ at lump $i$.

For each species $s$, there is one transport equation to be solved respectively

$$
\begin{gathered}
\frac{m_{i} y_{s, i}^{n+1}-m_{i} y_{s, i}}{\Delta t}+\sum_{\ell=1}^{\text {outward }} \max \left(-\dot{m}_{\ell}, 0\right)\left(y_{s, i}^{n+1}-y_{s, d w \ell}^{n+1}\right) \\
-\sum_{j=1}^{\text {inward }} \max \left(\dot{m}_{j}, 0\right)\left(y_{s, i}^{n+1}-y_{s, u w j}^{n+1}\right) \\
=\sum_{\ell=1}^{\text {outward }}\left[\frac{\left(\mu+\mu_{t}\right)_{\ell}}{S c} \frac{A_{\ell}}{L_{\ell}}\left(y_{s, d w \ell}-y_{s, i}\right)\right] \\
+\sum_{j=1}^{\text {inward }}\left[\frac{\left(\mu+\mu_{t}\right)_{j}}{S c} \frac{A_{j}}{L_{j}}\left(y_{s, u w j}-y_{s, i}\right)\right] \\
+\dot{\omega}_{s, i} V_{i}+\dot{\Omega}_{s, i} V_{i}
\end{gathered}
$$


The fluid network based GDE is written as

$$
\begin{gathered}
\frac{V_{i} N_{k, i}^{n+1}-V_{i} N_{k, i}}{\Delta t}+\sum_{\ell=1}^{\text {outward }} \max \left(-A_{\ell} u_{\ell}, 0\right)\left(N_{k, i}^{n+1}-N_{k, d w \ell}^{n+1}\right) \\
-\sum_{j=1}^{\text {inward }} \max \left(A_{j} u_{j}, 0\right)\left(N_{k, i}^{n+1}-N_{k, u w j}^{n+1}\right) \\
=-V_{i} \sum_{\ell=1}^{\text {outward }}\left[\frac{4 V_{d, \ell}}{D_{h \ell}} N_{k, d w \ell}\right] \\
-V_{i} \sum_{j=1}^{\text {inward }}\left[\frac{4 V_{d, j}}{D_{h j}} N_{k, u w j}\right] \\
+\left.V_{i} \frac{\Delta N_{k, i}}{\Delta t}\right|_{\text {micro }} \\
k=1, \cdots, M_{B}
\end{gathered}
$$

where $N_{k}$ is the number density of particles in size bin $k$ (the unit is $\# / m^{3}$ ), $k$ loops from 1 to the maximum number $\left(M_{B}\right)$ of sections for each particle size distribution, $V_{d}$ is the deposition velocity in a path, and $D_{h}$ the hydraulic diameter of a path.

$\left.\frac{\Delta N_{k}}{\Delta t}\right|_{\text {micro }}$ is the summation of microphysical processes which contribute to the production and loss of the particles,

$$
\begin{aligned}
\left.\frac{\Delta N_{k}}{\Delta t}\right|_{\text {micro }}=\left.\frac{\Delta N_{k, i}}{\Delta t}\right|_{\text {thermolphoresis }}+\left.\frac{\Delta N_{k, i}}{\Delta t}\right|_{\text {coagulation }} & \\
& +\left.\frac{\Delta N_{k, i}}{\Delta t}\right|_{\text {nucleation }}+\left.\frac{\Delta N_{k, i}}{\Delta t}\right|_{\text {cond.levap. }}
\end{aligned}
$$

Finally, the solution of all the transport equations leads to

$$
[A][\phi]=[B]
$$

where $[A]$ is a diagonal-dominated matrix, $[B]$ is the source vector, and $\phi$ is the solution vector. Equation (18) is solved here iteratively using a point-implicit relaxation method due to the unstructured nature of the fluid network.

\section{Experiment}

Recently, laboratory tests have been conducted to better understand the sources of the significant variations in the measured size and concentration of particles in the jet engine exhaust among several sampling and measurement approaches. The APEX-3 sampling line efficiency results are presented in reference 7 . Line loss measurements for different tubing sizes and sample flow rates are reported in reference 8 .

In reference 7, the particle loss characteristics of the sampling lines used in the APEX-3 field measurements were examined in a laboratory environment. The goal was to quantify the particle 
penetration efficiency as a function of the particle diameter. In these tests, monodisperse particles were generated by a tube furnace, and two well characterized particle instruments were used, one was connected to the entrance of the tested sampling line, the other to the exit of the tested line. The particle penetration efficiency of the sampling line is defined as the ratio of the measured downstream particle number density to the measured upstream particle number density. The layout of the test sampling lines has the same geometries as used in the field measurements. Two sets of data were obtained in the laboratory tests, one is for the case of the so called $1 \mathrm{~m}$-probe line, i.e., the aerosol probe is located at 1 meter downstream from the exit plane of the aircraft engine, the other one is for the case of the 30-m probe line. Schematics of the test setup can be found in the Appendix.

In reference 8 , the monodisperse particles were generated from a premixed flat flame burner. The particle penetration efficiency as a function of the particle diameter has been investigated for different material, length, diameter, and flow rate of the sampling line. A comprehensive line loss data sets are being compiled, and we have selected the test number 26 and test number 34 for modeling and simulation. The sampling lines are made of stainless steel, but they have different sizes, lengths, and flow rates.

\section{Assessment Results}

Four line loss experimental data sets are used for assessing the microphysical models currently in the NCC. These data sets are denoted as the APEX3 1-m probe sampling line (ref. 7), the APEX3 30-m probe sampling line (ref. 7), the UTRC test 26 sampling line (ref. 8), and the UTRC test 34 sampling line (ref. 8). Monodisperse particles have been used in all of these tests. And, for the flow conditions and the particle size range tested, the experimental data strongly suggest that diffusion of particles to the walls is the primary particle loss mechanism, other effects, such as the bends in sampling line, are negligible.

Three different levels of simulation have been carried out: CFD-based simulation, network-based simulation, and lower-order temporal simulation. It should be noted here that all of them use the same chemical and microphysical models. Each calculation requires the specification of particle size distribution and concentration at the entrance of the sampling line, and, instead of monodisperse particles, we have used polydisperse particles for all of the numerical simulations. The 12-bin discrete distribution of these polydisperse particles is given in table 1. Calculations in which all of the chemistry and microphysical models for the particles were "turned on" have been performed, and the results are very much the same as those from the calculations which include only the effects of particle diffusion. This is consistent with the experimental suggestion that diffusion of particles to the walls is the primary loss mechanism in the cases considered, and other effects, such as coagulation among particles, are insignificant. It is mentioned here that the results presented in the following are obtained by using polydisperse particles with the option of coagulation being "turned off" in the calculations.

TABLE 1.-DISTRIBUTION OF PARTICLE SIZE AND NUMBER DENSITY

\begin{tabular}{|l|c|r|}
\hline Bin number & $\begin{array}{c}\text { Diameter, } \\
(\mathrm{nm})\end{array}$ & \multicolumn{1}{|c|}{$\begin{array}{c}\text { Number density, } \\
\left(\# / \mathrm{m}^{3}\right)\end{array}$} \\
\hline 1 & 3 & 8585090 \\
\hline 2 & 4.48 & 10742262056 \\
\hline 3 & 6.7 & 95160588390 \\
\hline 4 & 10 & 315315201902 \\
\hline 5 & 15 & 390804103104 \\
\hline 6 & 22.4 & 181175611146 \\
\hline 7 & 33.5 & 31417148866 \\
\hline 8 & 50 & 2037793720 \\
\hline 9 & 74.8 & 49440184 \\
\hline 10 & 112 & 448669 \\
\hline 11 & 167 & 1220 \\
\hline 12 & 250 & \\
\hline
\end{tabular}




\section{1-m particle probe sampling line}

Since it is known that the effect of bends in the line on the particle loss is insignificant in this case, we consider a straight pipe consisting of two segments with different diameters. The total length of the sampling line is $23.5 \mathrm{~m}$. The internal diameter of the first $9.5 \mathrm{~m}$ segment is $0.009525 \mathrm{~m} \mathrm{(3/8} \mathrm{in.).} \mathrm{The}$ internal diameter of the second $14 \mathrm{~m}$ segment is $0.019050 \mathrm{~m}(3 / 4 \mathrm{in}$.). The CFD-based simulation assumes the flow is axisymmetric, and a total of 57,680 quadrilaterals are used to discretize the computational domain. Figure 1 shows a part of the mesh. The grid distribution used to conduct the lower-order temporal simulation is shown in figure 2, the number of grid points is 40 . Similar arrangement is used in the fluid network simulation, i.e., there are 40 lumps and 39 paths.

The incoming flow rate is 50 liter per minute; hence, the equivalent inlet velocity is $11.7 \mathrm{~m} / \mathrm{s}$. The temperature of the carrier gas is $295 \mathrm{~K}$. The upstream pressure is 740 Torr $(98627.2 \mathrm{~Pa}$ ). The downstream pressure is 690 Torr $(91963.2 \mathrm{~Pa})$. Computed results and the experimental data in terms of the particle penetration efficiency are presented in figure 3. The parameter "a" used in the CFD-based simulation accounts for the sticking effect of the wall. The value of $a=0.5$ means that the number density of the particles at the wall is half of the value at the nearest cell. Figure 3 indicates that, for smaller particles (say, $d<10-20 \mathrm{~nm}$ ), temporal and fluid network methods over-predict the penetration efficiency, while CFD-based method under-predicts the penetration efficiency. For larger particles, all three methods provide reasonably good results.

Figure 1.-Schematic of the mesh used in the CFD-based simulation.

Figure 2.-Schematic of the grid distribution used in the lower-order temporal simulation

APEX3 1m-probe line loss (Monodisperse aerosol source)

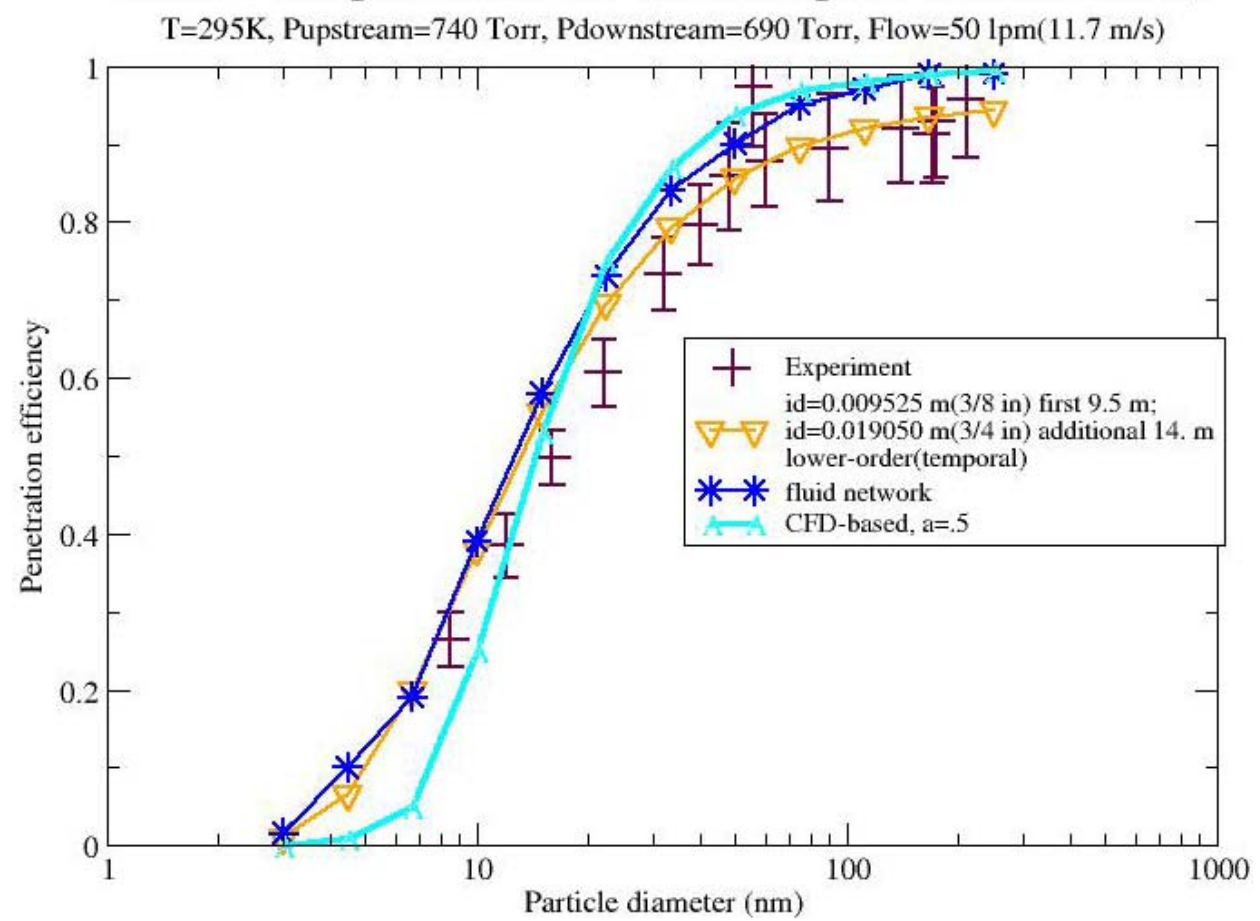

Figure 3.-Line loss comparison: flow rate $=50 \mathrm{LPM}$, inside diameter $=0.009525 \mathrm{~m}$ for the first $9.5 \mathrm{~m}$ segment, inside diameter $=0.01905 \mathrm{~m}$ for the second $14 \mathrm{~m}$ segment, $\mathrm{T}_{\text {gas }}=295 \mathrm{~K}, \mathrm{P}_{\text {out }}=91963 \mathrm{~Pa}$. 


\section{0-m particle probe sampling line}

The simulated sampling line is a straight pipe with an internal diameter of $0.01905 \mathrm{~m}(3 / 4 \mathrm{in}$.). The total length of the sampling line is $35 \mathrm{~m}$. The incoming flow rate is 50 liter per minute. Thus, the equivalent inlet velocity is $2.9 \mathrm{~m} / \mathrm{s}$. The temperature of the carrier gas is $295 \mathrm{~K}$. The upstream pressure is 740 Torr $(98627.2 \mathrm{~Pa})$, and the downstream pressure is 720 Torr $(95961.6 \mathrm{~Pa})$. Computed penetration efficiency of the particles and its experimental counterpart are presented in figure 4. For smaller particles (say, $d<30-40 \mathrm{~nm}$ ), all methods, except for the fluid network method with modified slip factor, overpredict the penetration efficiency. For larger particles, all methods yield reasonably good results.

The number of grid points used in the lower-order temporal simulation is 50 . The fluid network simulation uses 50 lumps and 49 paths. Two different meshes are used for the CFD-based simulation: 75,040 quadrilaterals used in an axisymmetric simulation and 380,160 hexahedrons used in a threedimensional simulation.

In the CFD-based simulations, in stead of using the gradient of particle number density to compute the molecular diffusion near the wall, we now take the approach of using the deposition velocity to compute the diffusion flux near the wall. Consequently, the value of the parameter "a" is now set to zero.

Figure 4 also demonstrates the effect of the so called slip factor on the results obtained from the fluid network simulation. Typically, the Cunningham-slip factor is defined as

$$
C c_{i}=1+K n_{i}\left(1.257+0.4 e^{-1.1 / K n_{i}}\right)
$$

where $K n_{i}$ is the Knudsen number defined as the ratio of the mean free path of the carrier gas, $\lambda_{\mathrm{g}}$, to the diameter of the size-i particle

APEX3 30m-probe line loss (Monodisperse aerosol source)

$\mathrm{T}=295 \mathrm{~K}$, Pupstream=740 Torr, Pdownstream=720 Torr, Flow $=501 \mathrm{pm}(2.9 \mathrm{~m} / \mathrm{s})$

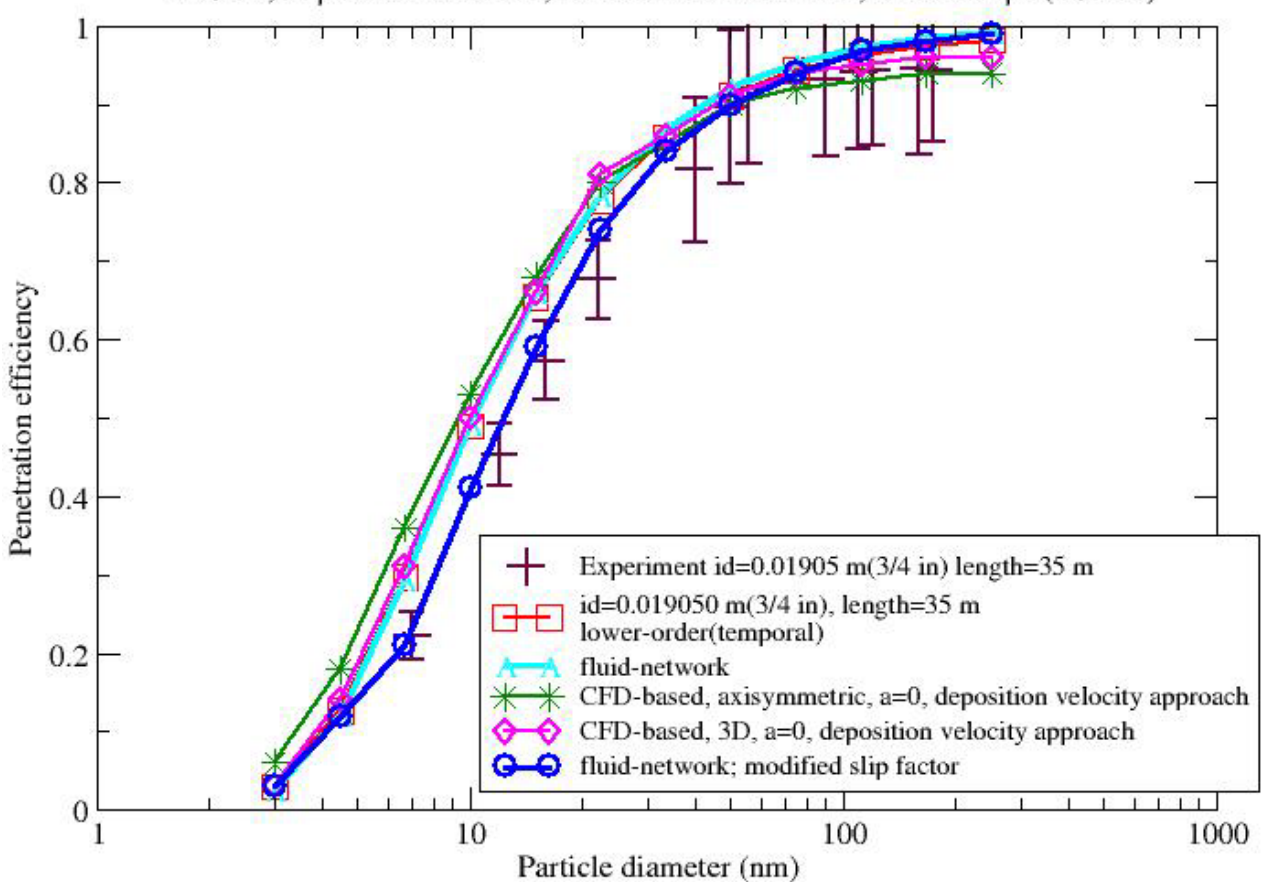

Figure 4.-Line loss comparison: flow rate $=50$ LPM, inside diameter $=0.019050 \mathrm{~m}$, Length $=35 \mathrm{~m}, \mathrm{~T}_{\text {gas }}=299 \mathrm{~K}, \mathrm{P}_{\text {out }}=95961 \mathrm{~Pa}$. 


$$
K n_{i}=\frac{2 \lambda_{g}}{d_{p, i}}
$$

The mean free path of the carrier gas depends upon the pressure, temperature, molecular weight of the carrier gas, and the universal gas constant.

It is observed that, for smaller particles, equation (19) leads to values of $C c_{i}$ which are much larger than one, while for larger particles, the values are close to one. To allow more control of the values of this empirical parameter, equation (19) is modified as

$$
C c_{i}=1+K n_{i}\left(1.257+0.4 e^{-1.1 / K n_{i}}\right) \times \mathrm{b}_{i}
$$

where $b_{i}$ is an particle-size dependent parameter. Experiences show that, generally speaking, when $b_{i}$ is larger than one, it leads to a reduction in the computed penetration efficiency. In the present simulation, values between 1.0 and 1.2 are specified for $b_{i}$, depending on the particle size range.

\section{UTRC Test 26 sampling line}

The tested sampling line is a straight pipe having an internal diameter of $0.0081026 \mathrm{~m}(0.319 \mathrm{in}$.). The total length of the sampling line is $15.24 \mathrm{~m}$. The incoming flow rate is 50 liter per minute. Thus, the equivalent inlet velocity is $16.2 \mathrm{~m} / \mathrm{s}$. The temperature of the carrier gas is $298.6 \mathrm{~K}$. The upstream pressure is 648.9 Torr $(86512 \mathrm{~Pa})$, and the downstream pressure is 540.2 Torr $(72020 \mathrm{~Pa})$.

The CFD-based simulation assumes axisymmetric flow, and 34,720 quadrilaterals are used for the mesh. The number of grid points used in the lower-order temporal simulation is 31 , the fluid network simulation uses 31 lumps and 30 paths. Computed as well as measured penetration efficiency are shown in figure 5. For smaller particles (say, $\mathrm{d}<10 \mathrm{~nm}$ ), all numerical methods predict similar results. For larger particles, both CFD-based simulation and lower-order temporal simulation under-predict the penetration efficiency with respect to the experimental data. The results from the fluid network simulations compare well with the measured data.

\section{UTRC Test 34 sampling line}

The tested sampling line is a straight pipe having an internal diameter of $0.011684 \mathrm{~m}(0.460 \mathrm{in}$.). The total length of the sampling line is $30.48 \mathrm{~m}$. The incoming flow rate is 72.5 liter per minute; hence, the equivalent velocity is $11.3 \mathrm{~m} / \mathrm{s}$. The temperature of the carrier gas is $299.9 \mathrm{~K}$. The upstream pressure is 632.5 Torr (84324 Pa), and the downstream pressure is 551.6 Torr (73539 Pa).

The CFD-based simulation is assumed to be axisymmetric, and the mesh has 75,040 quadrilaterals. The lower-order temporal simulation uses 46 grid points. The fluid network simulation uses 46 lumps and 45 paths. Computed and measured penetration efficiencies are presented in figure 6 . The predictions from the fluid network simulation with modified slip factor and the lower-order temporal simulation agree with the experimental data very well. The result from the fluid network simulation without modified slip factor over-predicts the penetration efficiency. 


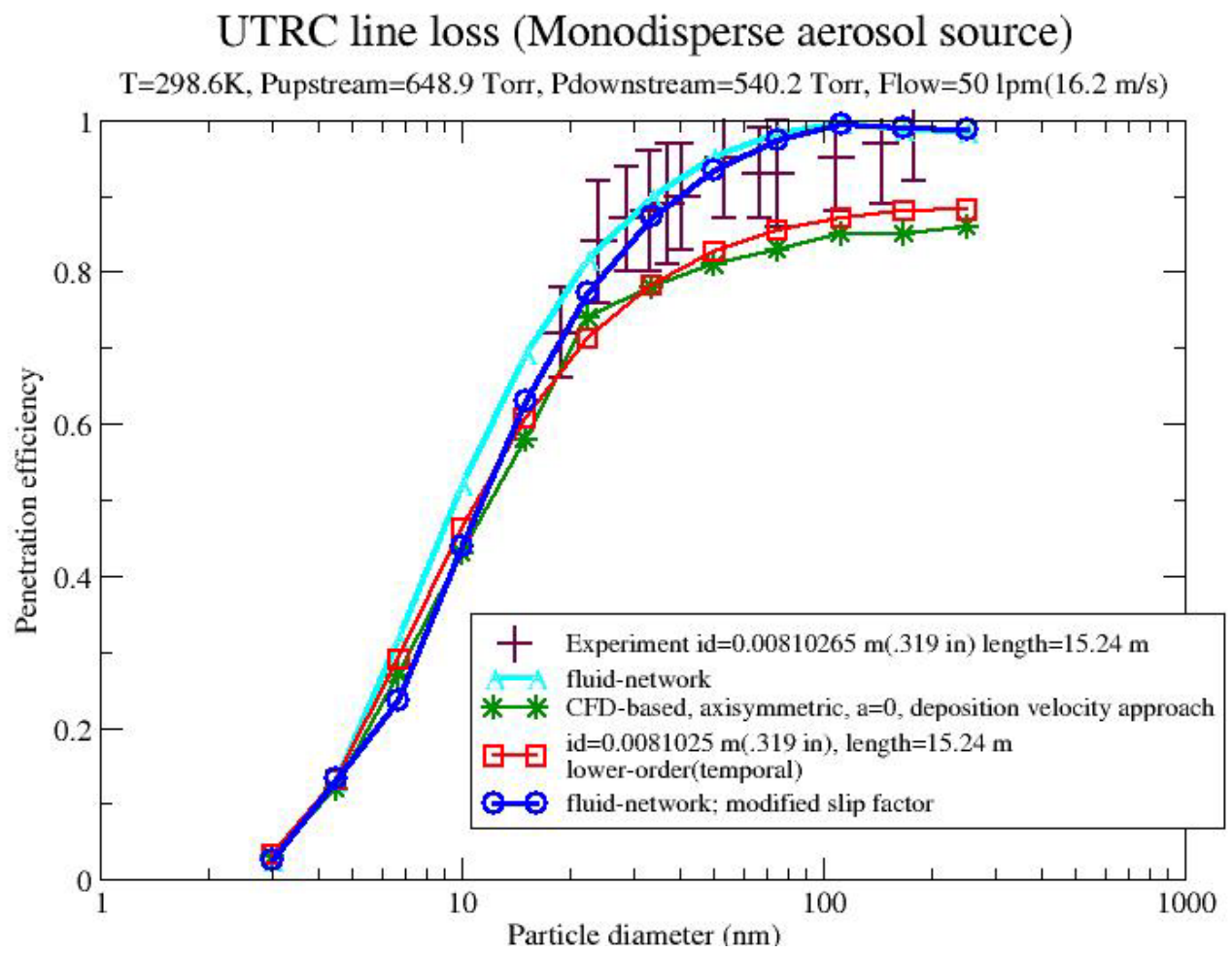

Figure 5. - Line loss comparison: flow rate $=50 \mathrm{LPM}$, inside diameter $=0.00810265 \mathrm{~m}$, Length $=$ $15.24 \mathrm{~m}, \mathrm{~T}_{\text {gas }}=298.6 \mathrm{~K}, \mathrm{P}_{\text {out }}=72042 \mathrm{~Pa}$.

UTRC line loss (Monodisperse aerosol source)

$\mathrm{T}=299.9 \mathrm{~K}$, Pupstream=632.5 Torr, Pdownstream=551.6 Torr, Flow=72.5 $1 \mathrm{pm}(11.3 \mathrm{~m} / \mathrm{s})$

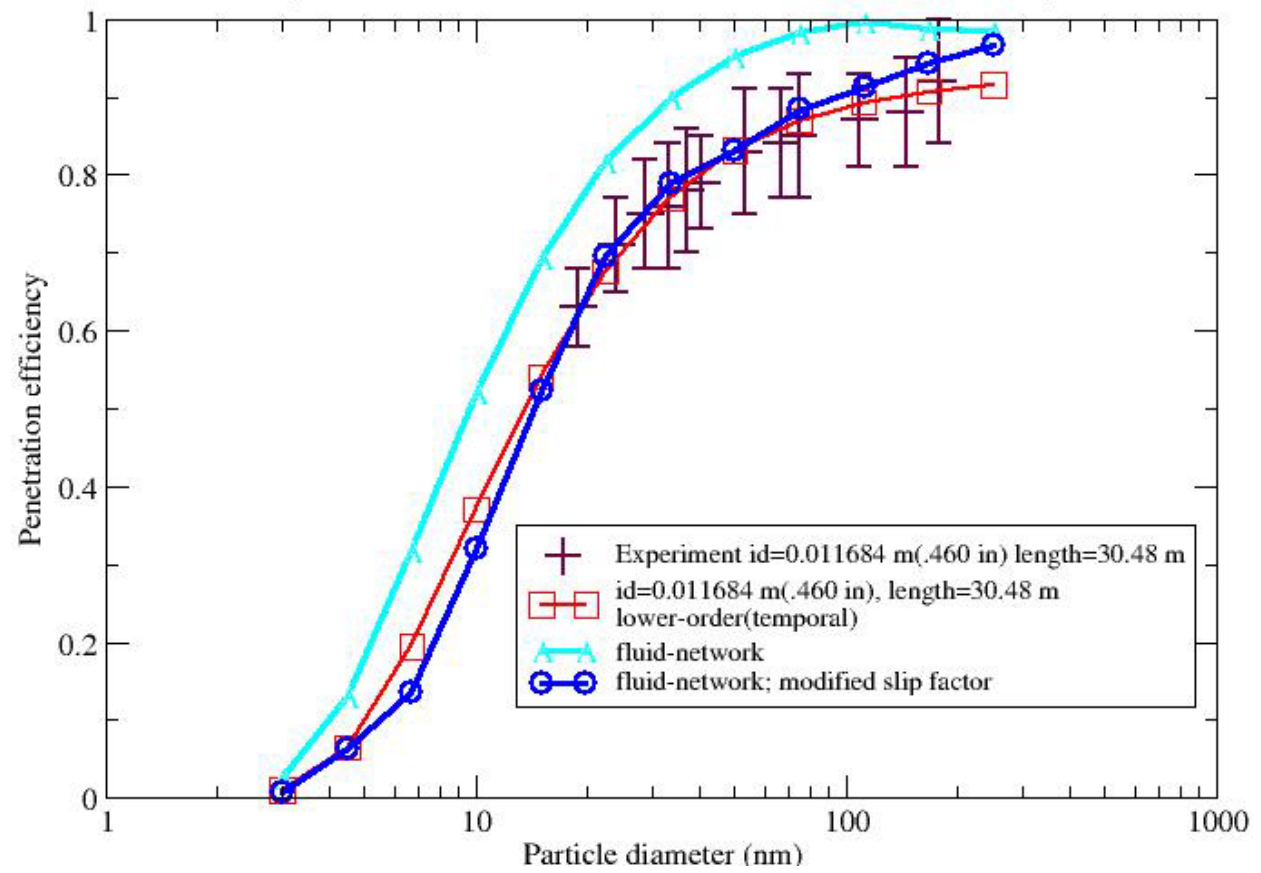

Figure 6. - Line loss comparison: flow rate $=72.5$ LPM, inside diameter $=0.011684 \mathrm{~m}$, Length $=$ $30.48 \mathrm{~m}, \mathrm{~T}_{\text {gas }}=299.9 \mathrm{~K}, \mathrm{P}_{\text {out }}=73539 \mathrm{~Pa}$. 


\section{Concluding Remarks}

A fluid network simulation capability is now available in the NCC. Together with the previously available CFD-based simulation capability and the lower-order temporal simulation capability, we now have a suite of computational tools which are versatile and cost effective for the modeling and simulation of transport of aerosols in the various flow paths, such as the engine internal passages, the sampling probes, the sampling lines, and the plumes. The focus of the present effort is the assessment of these three levels of simulation when applied to the prediction of particle loss in the sampling lines used in the measurement of particulate matter size and concentration in high-temperature, high-velocity jet engine exhaust. The predicted particle penetration efficiencies have been compared with the corresponding experimental data from four different laboratory tests. Generally speaking, the predicted results agree well with the measured data, when the particle diameters are larger than, say, $30 \mathrm{~nm}$. Based on the results obtained so far, among the three simulation approaches, the fluid network approach with modified slip factor seems to be the optimum choice for the modeling and simulation of the sampling line system. In addition to help establish standard methodologies for measuring the size and concentration of particles in the jet engine exhaust, the present work also represents the first step of a long term effort of validating physics-based tools for the prediction of aircraft particulate emissions. Obviously, this requires the acquirement of particulate emissions data specifically for the purpose of validating the microphysical models for aerosols.

\section{References}

1. Wey, T. and Liu, N.-S., "Modeling of Aerosols in Post-Combustor Flow Path and Sampling System," NASA/TM-2006-214397, September 2006.

2. Wey, T.C. and Liu, N.-S., "Modeling Jet Engine Aerosols in the Postcombustor Flow Path and Sampling System," Journal of Propulsion and Power, vol. 23 no. 5 September-October 2007, pp. 930-941.

3. Wey, T.C. and Liu, N.-S., "Streamline-Based Modeling of Aerosol Microphysics in the PostCombustor Flow Path and Sampling System," AIAA Paper 2007-0794, 45th AIAA Aerospace Sciences, Meeting and Exhibit, January 8-11, 2007, Reno, NV.

4. Wey, C.C., Anderson, B.E., Wey, C., Miake-Lye, R.C., Whitefield, P., and Howard, R., "Overview on the Aircraft Particle Emissions Experiment," Journal of Propulsion and Power, vol. 23 no. 5 September-October 2007, pp. 898-905.

5. C\&R Technologies, "SINDA/FLUINT General Purpose Thermal/Fluid Network Analyzer Version 5.0,” User's manual, Oct. 2006, Littleton Colorado.

6. Majumdar, A., "Generalized Fluid System Simulation Program (GFSSP) Version 3.0," November 1999, Sverdrup Technology, Inc. Huntsville, AL.

7. Anderson, B.E., "Preliminary Results of the APEX-3 Sampling Line/Probe Efficiency Tests," JETSAPEX2 and APEX3 Conference, November 29-December 1, 2006, North Olmsted, OH.

8. Liscinsky, D.S., "Effect of Particle Sampling Technique and Transport on Particle Penetration at the High Temperature and Pressure Conditions found in Gas Turbine Combustors and Engines," NASA Subsonic Fixed Wing NRA Annual Review, February 12, 2008. 



\section{Appendix-Laboratory Test of APEX-3 Sampling Lines}

To determine the particle loss characteristics of the sampling lines used in the APEX-3 field measurements, laboratory tests were conducted to quantify the particle penetration efficiency as a function of the particle diameter. Monodisperse particles were generated by a tube furnace. Two well characterized particle instruments are used, one is connected to the entrance of the tested sampling line, the other is connected to the exit of the tested line. The particle penetration efficiency of the sampling line is the ratio of the measured downstream particle number density to the measured upstream particle number density.

The layout of the test sampling lines has the same geometries as used in the field measurements. Two sets of data were obtained in the laboratory tests, one is for the case of the $1 \mathrm{~m}$-probe line, i.e., the aerosol probe is located at $1 \mathrm{~m}$ downstream from the exit plane of the aircraft engine, the other one is for the case of the $30-\mathrm{m}$ probe line.

The following schematics are taken from reference 7 to illustrate the laboratory line test setup, the layout and geometry of the $1 \mathrm{~m}$-probe line, and the layout and geometry of the $30-\mathrm{m}$ probe line:

\section{Laboratory test}

\section{Line Loss Test Setup}

\section{System was carefully leak-checked to minimize stray particle counts to allow going to high sample dilutions/flow rates}

Monodisperse Aerosol

Source $(\mathrm{NaCl}$ from Tube

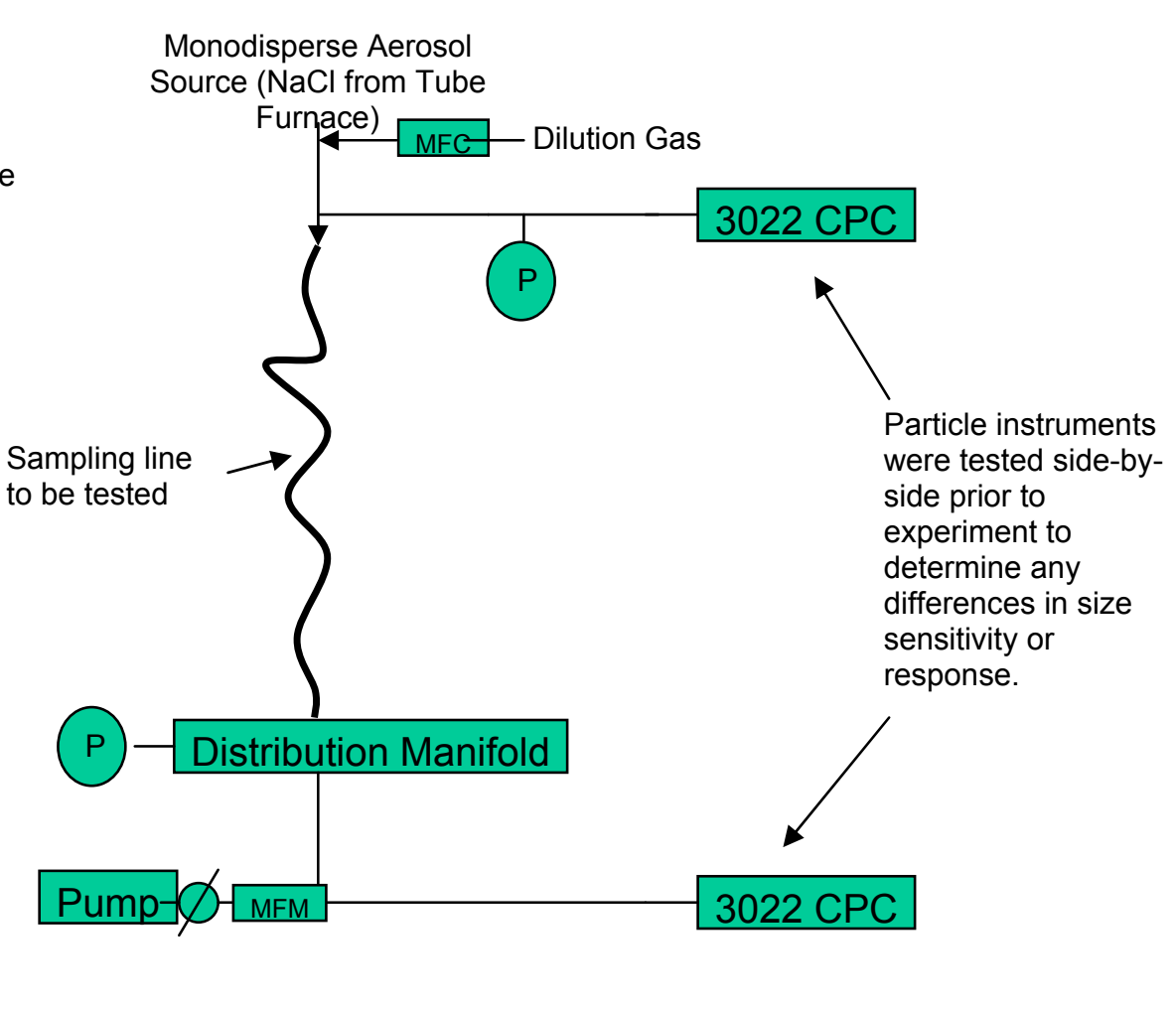

System flow was adjusted to simulate actual sampling conditions and to evaluate losses as a function of flow rate. 
APEX-3 1-m probe line

\section{APEX-3, Aerosol Sampling Line}

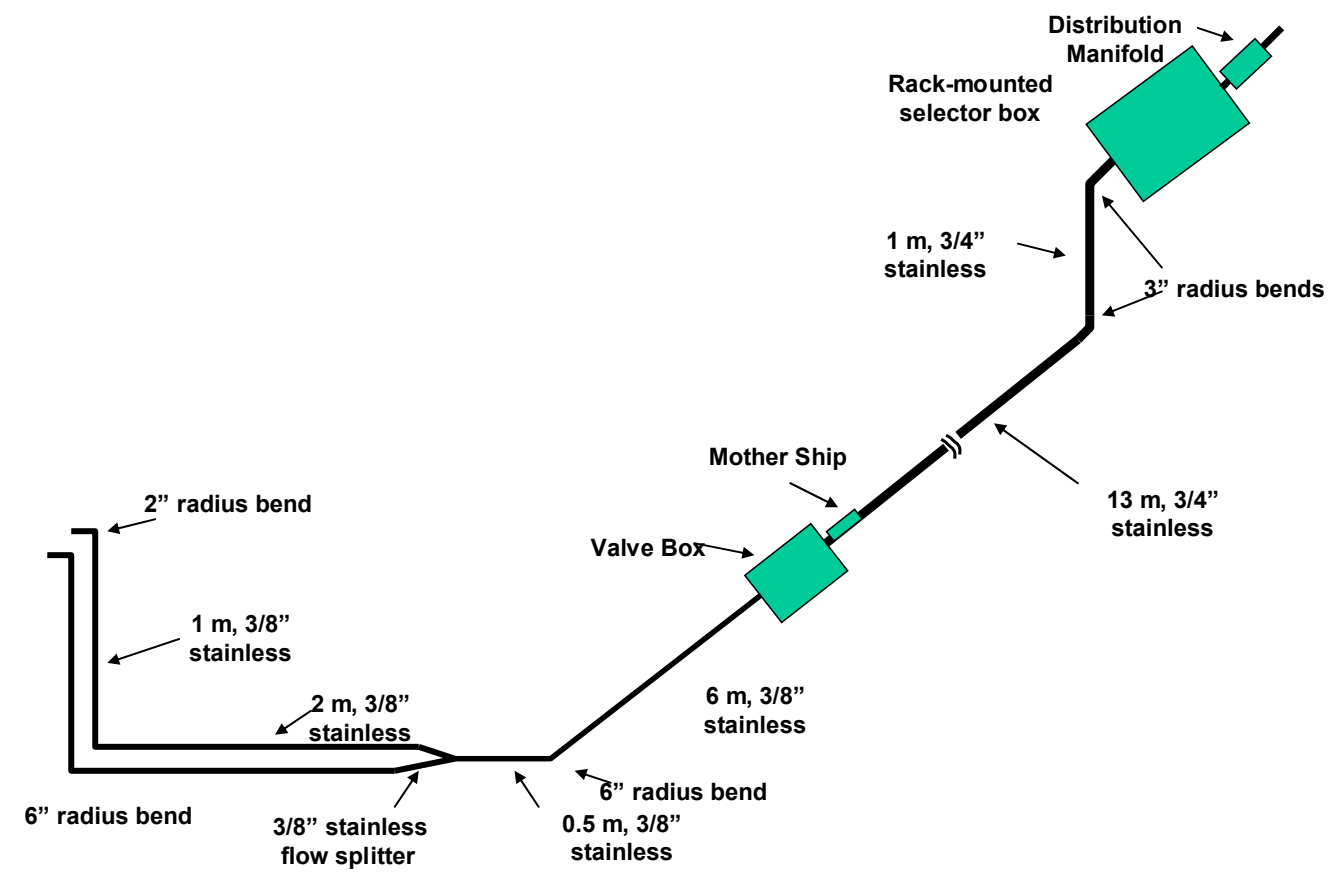

APEX-3 30-m probe line

\section{APEX-3, Aerosol Sampling Line}

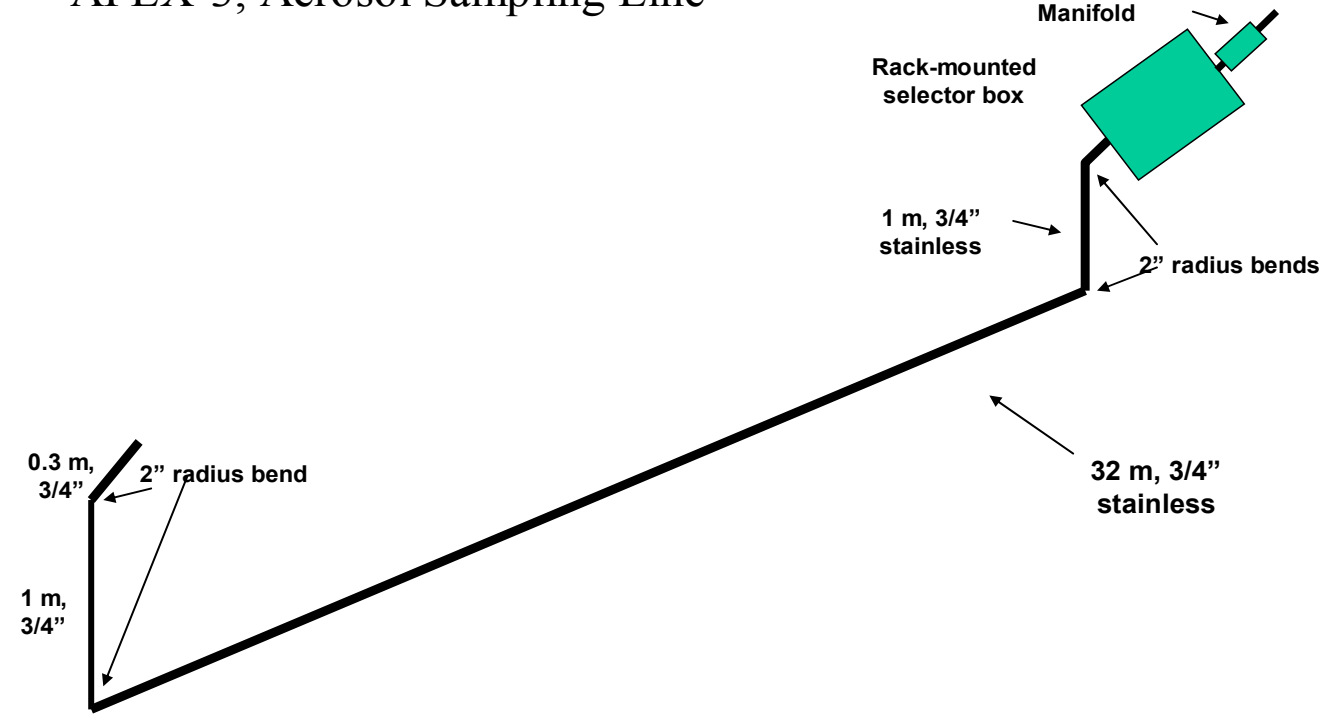




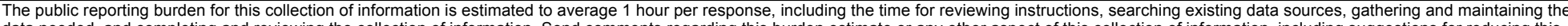

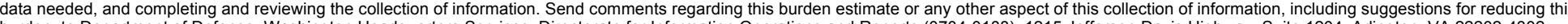

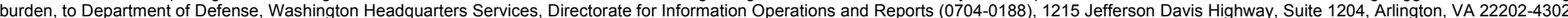

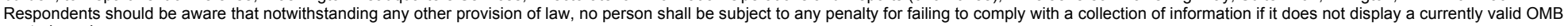
control number.

PLEASE DO NOT RETURN YOUR FORM TO THE ABOVE ADDRESS

\section{REPORT DATE (DD-MM-YYYY) \\ 2. REPORT TYPE \\ 3. DATES COVERED (From - To)}

01-10-2008

\section{TITLE AND SUBTITLE}

Technical Memorandum

Assessment of Microphysical Models in the National Combustion Code (NCC) for Aircraft

Particulate Emissions: Particle Loss in Sampling Lines

\section{5a. CONTRACT NUMBER}

5b. GRANT NUMBER

5c. PROGRAM ELEMENT NUMBER

6. AUTHOR(S)

Wey, Thomas; Liu, Nan-Suey

\section{5d. PROJECT NUMBER}

5e. TASK NUMBER

5f. WORK UNIT NUMBER

WBS 984754.02.07.03.19.02

8. PERFORMING ORGANIZATION

REPORT NUMBER

E-16575

National Aeronautics and Space Administration

John H. Glenn Research Center at Lewis Field

Cleveland, Ohio 44135-3191

\section{SPONSORING/MONITORING AGENCY NAME(S) AND ADDRESS(ES)}

National Aeronautics and Space Administration

Washington, DC 20546-0001

\section{DISTRIBUTION/AVAILABILITY STATEMENT}

Unclassified-Unlimited

Subject Category: 07

Available electronically at http://gltrs.grc.nasa.gov

This publication is available from the NASA Center for AeroSpace Information, 301-621-0390

\section{SUPPLEMENTARY NOTES}

\section{ABSTRACT}

This paper at first describes the fluid network approach recently implemented into the National Combustion Code (NCC) for the simulation of transport of aerosols (volatile particles and soot) in the particulate sampling systems. This network-based approach complements the other two approaches already in the NCC, namely, the lower-order temporal approach and the CFD-based approach. The accuracy and the computational costs of these three approaches are then investigated in terms of their application to the prediction of particle losses through sample transmission and distribution lines. Their predictive capabilities are assessed by comparing the computed results with the experimental data. The present work will help establish standard methodologies for measuring the size and concentration of particles in high-temperature, high-velocity jet engine exhaust. Furthermore, the present work also represents the first step of a long term effort of validating physics-based tools for the prediction of aircraft particulate emissions.

\section{SUBJECT TERMS}

Particulate matter emissions

\begin{tabular}{|c|c|c|c|c|}
\hline 16. SECURI & ASSIFICATION & & 17. LIMITATION OF & 18. NUMBER \\
\hline $\begin{array}{l}\text { a. REPORT } \\
\text { U }\end{array}$ & $\begin{array}{l}\text { b. ABSTRACT } \\
U\end{array}$ & $\begin{array}{l}\text { c. THIS } \\
\text { PAGE } \\
\text { U }\end{array}$ & UU & $\begin{array}{c}\text { PAGES } \\
22\end{array}$ \\
\hline
\end{tabular}

0. SPONSORING/MONITORS
ACRONYM(S)
NASA; AIAA
1. SPONSORING/MONITORING
REPORT NUMBER
NASA/TM-2008-215304; AIAA-2009-
0257
0257 

